\title{
Saliva Production Induction
}

National Cancer Institute

\section{Source}

National Cancer Institute. Saliva Production Induction. NCI Thesaurus. Code C41485.

Saliva Production Induction involves initiation of synthesis of the clear, slightly acid ( $\mathrm{pH}$

6.8) viscous fluid secreted from the parotid, sublingual, and submandibular salivary glands and the mucous glands of the oral cavity that contain mucins, water, organic salts, and ptylin and keep the oral mucous membrane moist, lubricate food, and partially convert starch into maltose. 